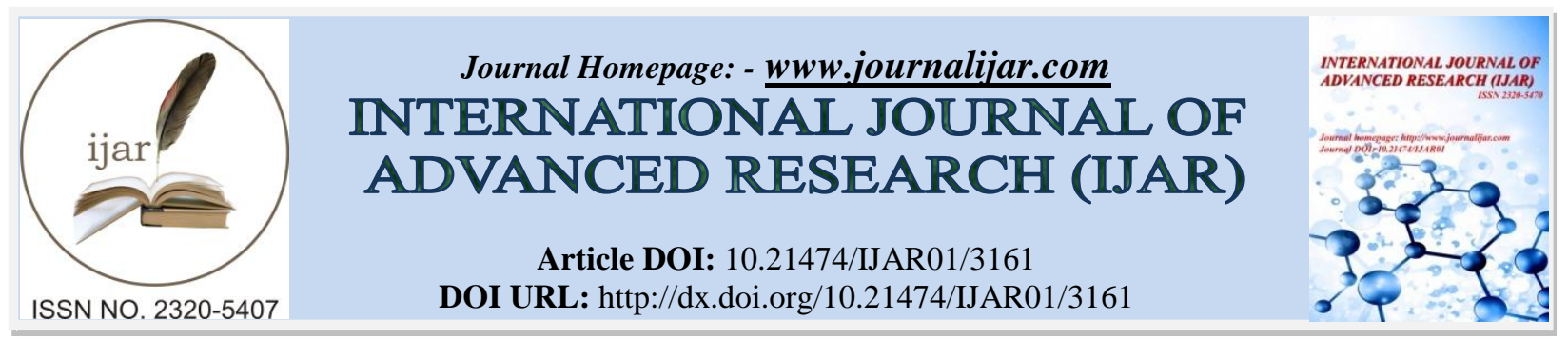

RESEARCH ARTICLE

\title{
Ocular Manifestations of Stevens-Johnson Syndrome
}

Kawthar Mohammed Alshammari, Jluwi Al masaud, Hasna Alghubaini, Reem Alshammari and Sarah Alrashidi.

\section{Manuscript Info}

Manuscript History

Received: 14 December 2016

Final Accepted: 10 January 2017

Published: February 2017

\section{Abstract}

Copy Right, IJAR, 2017,. All rights reserved.

\section{Introduction:-}

Stevens-Johnson syndrome (SJS) is a mucocutaneous reactions, most commonly triggered by medications, characterized by extensive necrosis and detachment of the epidermis.

Fever, often exceeding $39^{\circ} \mathrm{C}\left(102.2^{\circ} \mathrm{F}\right)$, influenza-like symptoms precede by one to three days the development of mucocutaneous lesions [70]. Photophobia, itching or burning conjunctiva and pain on swallowing may be early symptoms of mucosal involvement. Malaise, myalgia, and arthralgia are present in most patients.

Ocular involvement is reported in approximately 80 percent of patients. The most common change in the eyes is a severe conjunctivitis with a purulent discharge, but bullae may develop. Corneal ulceration is frequent, anterior uveitis or panophthalmitis may occur. Pain and photophobia are accompanying symptoms. The eye changes often regress completely, but scarring with the development of synechiae between the eyelids and conjunctiva may be late sequelae $[80,81]$.

\section{Case Report:-}

46 years old female patient came with sever eye dryness and epithelial defect. She had a history of knee pain 1 month and 20 days back for which she was treated with intramuscular voltaren in emergency department. She developed erythematous papular eruptions on the trunk, mouth, and limbs along with pain, redness, and watering from both eyes followed by gross diminution of vision and inability to open her eyes. She was subsequently admitted at the king Khalid hospital and diagnosed with Stevens-Johnson syndrome by dermatologist . The erythematous lesions resolved completely at 4 weeks with medications, but she was unable to open her eyes and she was referred to us for further evaluation and management .

Ophthalmic Examination At the time of presentation:-

Visual acuity:- 20/400 OU

With full EOM

Eye lids and conjunctiva:- congested, red conjunctiva, mucopurulent discharge with membrane formation in superior and inferior fornix of conjunctiva . 
Intraocular pressure ( IOP):- $16 \mathrm{~mm}$ of $\mathrm{Hg} \mathrm{OU}$.

Slit lamp:- low tear meniscus, tear break-up time more than $10 \mathrm{~s}$

Cornea:- sever dryness with epithelial defect OU

AC:- Deep and quit OU

Iris:- Normal OU

Pupil:- Equal round reactive to light

Lens:- Early posterior sub-capsular cataract OU

B-scan ultrasonography (USG) : acoustically clear vitreous, normal chorioretinal thickness, and normal optic nerve head with an attached retina.

Routine blood examination, blood glucose levels were within normal limits.

The patient was treated for ocular condition with frequent debridement of pseudomembran in superior and inferior fornix to prevent symblepharon formation. At that time we do not have amniotic membrane, although we prescribed for her predforte eye drop for ten days, then optilon eye drop for two weeks, frequent lubrication with artificial tears and punctual plugs.

\section{Outcome and Follow-up:-}

Best corrected visual acuity improved to $20 / 50$ OU. The corneal epithelial defect healed, conjunctival pseudomembran regressed and improvement of the tear film. The patient follow up in ophthalmology clinic at king Khalid hospital with next appointment on fifteen of February 2017.

\section{Discussion:-}

This is the first case report in Hail, Saudi Arabia and there is Very little data is available on the prevalence of Ocular complications of Stevens-Johnson syndrome in general.

patients of SJS are treated by dermatologist in early phases and later referred to an eye care center. Patients often consult an ophthalmologist with severe ocular sequelae only after the resolution of skin lesions, as in our case. It obviously becomes challenging to diagnose and treat this disease .

Management is often effective . It involves keeping the eye moist and preserving the patient's own tears, as well as treating the underlying cause when found.

The selection of treatment modalities for patient with dry eye depends on the severity of their disease . Frequent use of lubricating eye drops and ointments. Punctual plugs always an option in treating dry eye.

\section{Conclusion:-}

In conclusion, a high index of suspicion and combined efforts from dermatologists and ophthalmologists with early treatment is important to improve prognosis and salvage the eye.

1. Bastuji-Garin S, Rzany B, Stern RS, et al. Clinical classification of cases of toxic epidermal necrolysis, StevensJohnson syndrome, and erythema multiforme. Arch Dermatol 1993; 129:92.

2. Roujeau JC. Stevens-Johnson syndrome and toxic epidermal necrolysis are severity variants of the same disease which differs from erythema multiforme. J Dermatol 1997; 24:726.

3. Roujeau JC, Stern RS. Severe adverse cutaneous reactions to drugs. N Engl J Med 1994; 331:1272.

4. Bircher AJ. Symptoms and danger signs in acute drug hypersensitivity. Toxicology 2005; 209:201.

5. Morales ME, Purdue GF, Verity SM, et al. Ophthalmic Manifestations of Stevens-Johnson Syndrome and Toxic Epidermal Necrolysis and Relation to SCORTEN. Am J Ophthalmol 2010; 150:505.

6. Gueudry J, Roujeau JC, Binaghi M, et al. Risk factors for the development of ocular complications of StevensJohnson syndrome and toxic epidermal necrolysis. Arch Dermatol 2009; 145:157. 